\title{
Neues Handbeschichtungsgerät
}

\section{Kurze Amortisation dank schneller Farbwechsel}

\section{Ein neues Handbeschichtungsgerät soll Farbwechsel dauerhaft in weniger als einer Minute ermöglichen.}

\author{
Der Lohnbeschichter Eisemann + Bähr testete das Gerät auf Herz und Nieren.
}

$D^{\mathrm{c}}$ er Lohnbeschichter Eisemann + Bähr aus Villingen-Schwenningen setzt seit Kurzem das neue Handbeschichtungsgerät OptiFlex2 Q von Gema ein. Dabei handelt es sich um eine Weiterentwicklung des bewährten Boxgeräts, das mit zwei sich ergänzenden Assistenzsystemen für den schnellen Farbwechsel ausgestattet wurde. „Da das bestellte Standardgerät einige Wochen Lieferzeit hatte, bekamen wir ein Leihgerät zur Überbrückung. Als dann mit diesem neuen Typ unglaublich kurze Farbwechselzeiten von 45 Se-

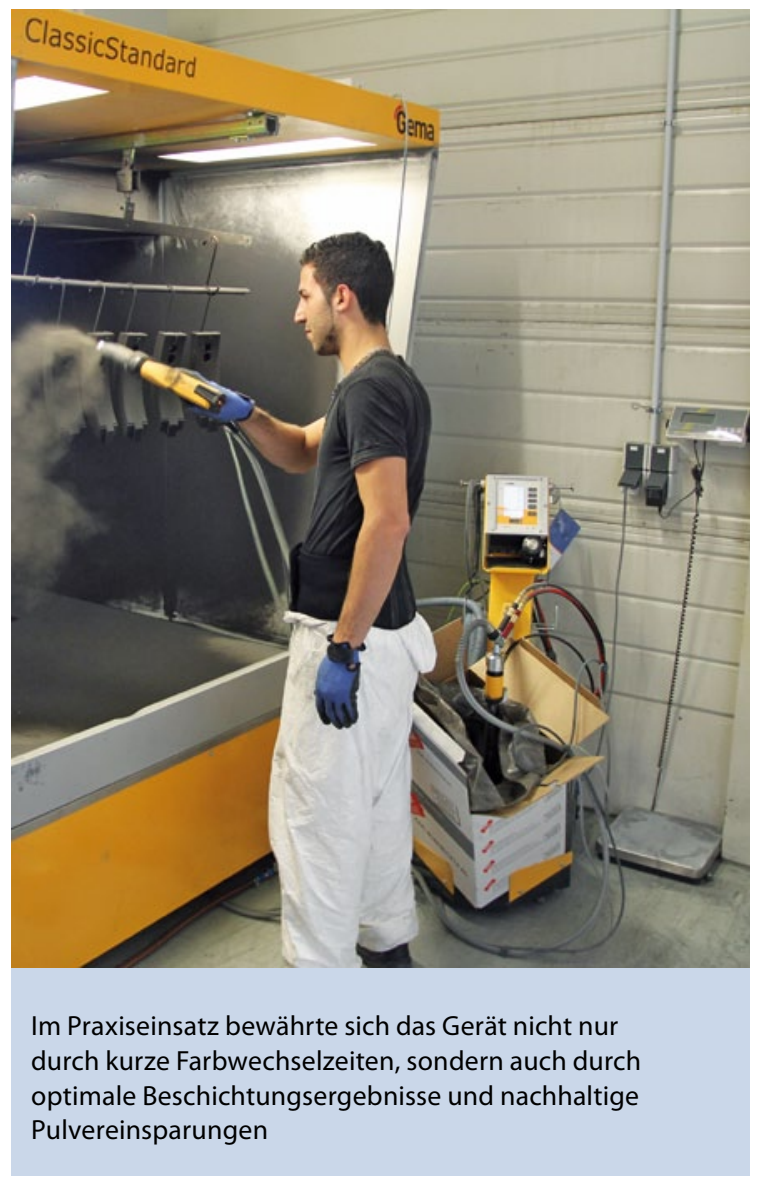

kunden demonstriert wurden, war unser Interesse geweckt“, sagt Geschäftsführer Marc Bähr.

Um sicherzugehen, dass diese Leistung nicht nur bei Vorführungen erzielt würde, testete Eisemann + Bähr das Gerät in den folgenden vier Wochen auf Herz und Nieren. „Mit dem bisherigen Gerät dauerte ein Farbwechsel jeweils vier bis fünf Minuten. Mit dem neuen erreichten wir jedoch konstant Zeiten unter einer Minute und sparen sogar noch 13 Prozent Pulver ein, ohne die Schichtdicken zu verändern", berichtet Marc Bähr.

Das neue Handbeschichtungsgerät verfügt über eine im Geräterahmen integrierte Absaugung für das Fluidansaugrohr. Dieses wird beim Hochziehen abgesaugt und die Pulverstäube werden über einen Abluftschlauch dem Filtersystem der Kabine zugeführt.

Das zweite Assistenzsystem ist für die Innenreinigung des gesamten Pulverweges von der Mündung des Ansaugrohres bis zur Düsenspitze zuständig. Dieser Vorgang wird am Gerät oder über die Pistole ausgelöst, worauf der Pulverschlauch entleert und mit zehn Druckluftstößen durchgeblasen wird.

Schon, während der zweite Schritt abläuft, kann der Pulverkarton

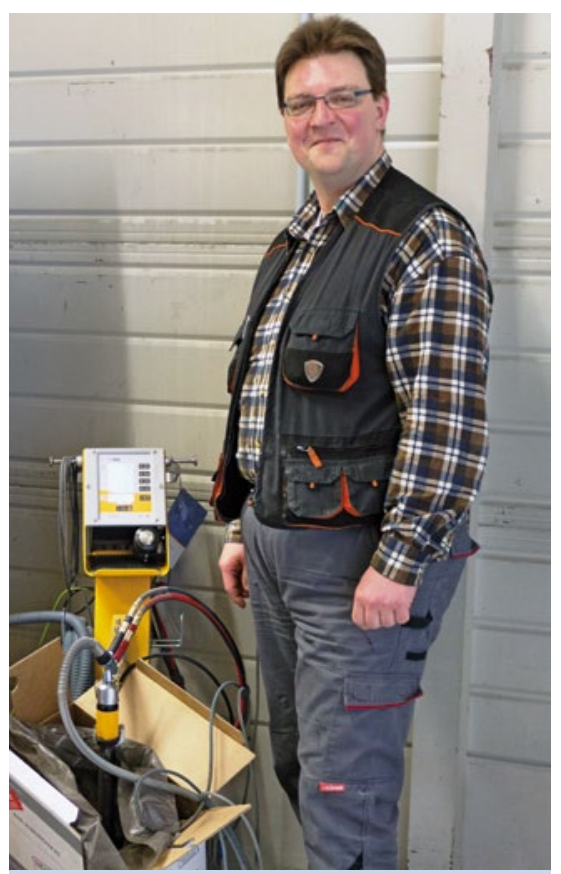

Eisemann + Bähr-Geschäftsführer Marc Bähr freut sich über die auf unter eine Minute reduzierten Farbwechselzeiten

ausgetauscht werden. Nach dem Abblasen der Pistole kann die Beschichtung mit dem nächsten Farbton weitergehen.

Eisemann + Bähr rechnete aus, dass allein durch die Zeitersparnis das Gerät in weniger als einem Jahr amortisiert sein würde. „Für uns ist das OptiFlex2 Q die perfekte Kombination von Wirtschaftlichkeit, Leistungsfähigkeit und Qualitätsbeschichtung. Darum haben wir uns auch gleich ein zweites Gerät angeschafft", zieht Bähr Bilanz. |

Kontakt:

Gema, Tel. 0607481944 0, www.gemapowdercoating.com 